\title{
Personality, Parental Behavior, and Attachment to Close Friends
}

\author{
Tea Pavin Ivanec ${ }^{1} \&$ Antonia Babojelić ${ }^{1}$ \\ ${ }^{1}$ Faculty of Teacher Education, University of Zagreb, Croatia \\ Correspondence: Tea Pavin Ivanec, Faculty of Teacher Education, University of Zagreb, Savska cesta 77, \\ Zagreb, Croatia.
}

Received: September 30, 2020

Accepted: October 28, 2020

Online Published: November 3, 2020

doi:10.5539/ijps.v12n4p19

URL: https://doi.org/10.5539/ijps.v12n4p19

\begin{abstract}
The aim of this study was to examine the relationship between young women's personality traits, perceived parental behavior of their parents, and the dimensions of attachment to close friends. Results generally indicated significant effects of personality traits and parental behavior on attachment to close friends. More specifically, agreeableness was a negative predictor of attachment anxiety, and neuroticism was a positive predictor of the same attachment dimension. Both agreeableness and extraversion were negative predictors of attachment avoidance. Parental behavior was predictive for attachment avoidance in close friendship, while there were no effects of parental behavior on attachment anxiety. Mothers' supportiveness and restrictive control were negative predictors of attachment avoidance, whereby fathers' support was a positive predictor of this attachment dimension. The results imply the importance of both personality and parental behavior as determinants of attachment to close friends and also suggest the need for further research of specific associations within the context of these broad theoretical constructs.
\end{abstract}

Keywords: attachment, close friendship, parental behavior, personality traits, young women

\section{Introduction}

Attachment theory introduced by Bowlby presents a broad and widely studied theory of building and maintaining close relationships with significant others throughout the lifespan (Rholes \& Simpson, 2015), emphasizing the role of caregivers for the development of emotional bonds. The quality of that bond influences attachment organization, which further affects various developmental outcomes. Attachment-related experiences and interactions affect the development of internal working models (representations of self and the world), and these working models reflect on behavior and expectations in future relationships (Bowlby, 1989). Thus, warm, available, and responsive caregivers foster the development of a secure internal working model, and securely attached children are more likely to initiate positive interactions with others and be confident. Additionally, these children perceive themselves more positively (Allen \& Tan, 2016; Keizer et al., 2019; Thompson, 2016), which also helps in initiating social interactions. On the other side, children whose caregivers are insensitive, unsupportive, or rejecting are more likely to develop an insecure internal working model characterized by avoiding others or, on the other side, by excessive attention-seeking (Fraley \& Roisman, 2015). Early attachment organization displays relative stability later in life, but it should be noticed that later attachment experiences can also initiate change in internal working models if the current working model contrasts with the prototypical working model (Lai \& Carr, 2018; Mikulincer \& Shaver, 2016). For example, an individual whose attachment to a caregiver is insecure, later in life, may develop a securely attached close relationship with a warm and caregiving person (romantic partner or a close friend). Numerous studies have demonstrated a positive correlation between adult attachment security and adaptive and functional emotional behavior (Chopik et al., 2019; Hershenberg et al., 2011), including an individual's functioning in different types of close relationships. Accordingly, comprehensive literature on individual differences in attachment organization emphasizes the importance of attachment insecurity for various externalizing problems in the future (Fransson et al., 2013), which also reflects on the quality of social interactions with others and the number of friends (Murakami, 2014). Individual differences in attachment style reflect on how people behave not only in friendships but in broader social networks as well (Gillath et al., 2017).

Studies measuring attachment include both categorical (attachment type) and dimensional (attachment dimensions) measures. Brenan et al. (1998) analyzed various attachment measures and concluded that they could be described by two attachment-related dimensions - attachment anxiety and attachment avoidance. Attachment anxiety refers to the level of an individual's concerns and doubts regarding the rejection and availability of an attachment figure 
(parent, partner, friend) when needed. Attachment avoidance relates to distrust and discomfort with intimacy, whereby a person attempts to be distant and independent from the attachment figure (Bartholomew, 1990; Brennan et al., 1998). Attachment dimensions have been frequently used and validated in the field of attachment research in adolescence and adulthood, especially within the context of romantic relationships. Based on attachment dimensions, individual attachment style can be defined as a secure type (low scores on both dimensions), or as preoccupied, fearful, or dismissing type (Bartholomew \& Horowitz, 1991; Mikulincer \& Shaver, 2016). The last three types can generally classify under the same denominator of insecure attachment.

Most frequently studied types of close relationships, depending on an individual's age, are certainly parent/caregiver-child relationship, romantic relationship, and close friendship. These three categories of close relationships are relevant social contexts in which attachment quality dominantly manifests. The focus of most attachment-theory related studies is undoubtedly the child-parent relationship. However, in the last few decades, there is a growing presence of studies exploring other close relationships in adulthood. Bowlby (1989) also accented the importance of adult attachment in emotional functioning, emphasizing that early attachment has a significant impact on later interpersonal relationships and demonstrates stability. Although the growing body of research on adult attachment primarily focuses on romantic relationships, researchers also recognize the role of close friendships since their importance grows throughout late childhood and adolescence. Indeed, these relationships in adolescence and emerging adulthood can be the most important for a young person's well-being (Amati et al., 2018; Harris \& Vazire, 2016; Rubin et al., 2004).

Trinke and Bartholomew (1997) highlighted the importance of friends as attachment figures during the transition to adulthood, and Scharfe et al. (2017) concluded similar when exploring the role of peers on adjustment to transition from the university. Close friendships are related to numerous developmental aspects, such as identity exploration, self-esteem, conflict management, and social competence in general. Close friendships also represent a shift in attachment from parents/caregivers to another person (Rholes \& Simpson, 2015; Zeifman \& Hazan, 2016). La Guardia et al. (2000) obtained that college students expressed overall greater attachment security with their best friend (compared to parents and romantic partners). Within the context of close friendships, studies also indicate that females are generally more oriented towards relations and seek higher intimacy and more self-emotional disclosure with their close friends (Gilespie et al., 2015; Hall, 2011).

Friendships are the context in which individuals learn how to be supportive and comfortable with being close to another person. The importance of intimacy, as a prerequisite of attachment security in close friendships, rises in adolescence and becomes even more salient during the transition to adulthood (Hartup \& Stevens, 1997), whereby experiences in close friendships may significantly influence the development of supportiveness and intimacy in later romantic relationships. As already mentioned, the characteristics and the importance of friendship vary during the life cycle. Accordingly, the importance of secure attachment to close friends becomes even more salient in the transitional period from adolescence into adulthood, i.e., in emerging adulthood (Arnett, 2000); a period when young people enter either higher education or labor market and face new (and potentially stressful) challenges. Hence, social support received from close friends plays a significant role in an individual's life (Miething et al., 2016).

Quality of attachment is explored in relation to various constructs, and individual differences in attachment quality are generally ascribed to individual characteristics, differences between attachment figures, characteristics of a particular relationship, and characteristics of a family (Buist et al., 2008). This paper focuses on the role of personality and perceived parental behavior in explaining young women's attachment to close friends. Studies indicate that both personality and parental behavior are associated with attachment in close relationships. Nonetheless, these constructs are usually addressed separately. Hence, the present study's contribution is in exploring the simultaneous effects of these characteristics on attachment dimensions. Also, this study aims at building upon existing knowledge on the attachment in close friendships that are, compared to romantic relationships, less represented in adult attachment research. Finally, this study also provides the opportunity to observe compliance of results with those obtained in various cultural contexts.

\subsection{Personality Traits and Attachment to Friends}

Among various individual characteristics, personality traits are certainly an important determinant of attachment quality in adulthood, suggesting the mediating effect of genetics on social relationship dynamics (Donnellan et al., 2008). Individual differences in attachment, especially in adult attachment, are often explored from the perspective of the Five-Factor Model, or the Big-Five Model (John et al., 2008). This model comprises five broad traits: extraversion (characteristics such as positive emotionality and sociability), agreeableness (which includes empathy, trust, altruism, and modesty), conscientiousness (referring to self-discipline and orderliness), openness 
(intellectualism and originality), and neuroticism (characteristics related to negative emotionality, such as irritability and anxiety). Cross-cultural validations have confirmed these traits, suggesting a universal personality-trait structure across cultures (McCrae \& Costa, 1997).

A substantial number of studies explored the relationship of attachment and personality dimensions, and demonstrated that particular relationships between the two constructs are relatively consistent, whereby some studies examined attachment dimensions (anxiety and avoidance), and another examined the type of attachment (secure and insecure type). On a sample of university students, Shaver and Brennan (1992) obtained that secure-type participants, compared to those whose attachment was insecure, had higher results on extraversion, agreeableness, and conscientiousness, and there was no difference between groups concerning openness. In a study conducted by Chung (2018), neuroticism positively correlated with attachment anxiety and attachment avoidance, and attachment avoidance negatively correlated with extraversion. Marušić et al. (2011) obtained that attachment anxiety was also positively predicted by neuroticism, while extraversion and agreeableness were negative predictors of avoidance in friendship. They also obtained a correlation between attachment avoidance and certain facets of openness. However, these correlations were attained only for the men and not for the women in their study. Franson et al. (2013) obtained a positive correlation of extraversion and openness with attachment security. On the other side, in their study openness was positively correlated with the disorganized attachment as well. In the study conducted by Shahrazad et al. (2015), openness and conscientiousness positively correlated with both secure and insecure attachment.

According to Noftle and Shaver (2006), studies generally indicate a moderate negative correlation of attachment security and neuroticism, moderate positive correlation with extraversion and agreeableness, and modest positive correlation with conscientiousness, while openness mostly does not correlate with attachment security. Their analysis also indicated that attachment anxiety shows moderate to strong correlation with neuroticism, while results regarding its correlation with extraversion, agreeableness, and conscientiousness are somewhat ambiguous; in some studies, these correlations are attained, but not in others. Further, extraversion and agreeableness are moderate to modestly correlated with attachment avoidance, and some studies reported a positive correlation of attachment avoidance with neuroticism and negative with conscientiousness. Neither attachment anxiety nor attachment avoidance correlated with openness. Noftle and Shaver (2006) obtained a positive correlation between neuroticism and both attachment anxiety and attachment avoidance of university students. Additionally, attachment anxiety negatively correlated with agreeableness, extraversion, conscientiousness, and openness. Analyzing longitudinal data, Young et al. (2017) obtained that participants who were in early childhood rated as securely attached had higher results on agreeableness and conscientiousness and lower result on neuroticism in adulthood. Concerning conscientiousness, Crawford, Shaver, et al. (2007) point out that even high conscientiousness can contribute to attachment anxiety due to an enhanced level of control and orderliness. Literature generally suggests that the effects of neuroticism and agreeableness on friendship are quite consistent, while the effects of other traits are somewhat inconsistent (Harris \& Vazire, 2016). Previous studies also indicate that the most consistent results and strongest correlations are between neuroticism and attachment anxiety. Mikulincer and Shaver (2016) observed that the majority of studies indicated a significant correlation between neuroticism and attachment anxiety, and the number of studies that obtained a significant correlation between neuroticism and attachment avoidance is about one-third smaller. Other correlations display more variations in their strength, significance, and even direction, hence implying the need for further research, especially having in mind that conclusions on adult attachment predominantly draws upon the context of romantic relationships.

\subsection{Parental Behavior and Attachment to Friends}

As already emphasized, emotional sensitivity and responsiveness of caregivers are crucial for the development of attachment organization. The caregiver's responsiveness and emotional warmth are related to secure attachment, while unresponsive and emotionally disengaged caregiving or maltreatment relate to insecure types of attachment (Ainsworth et al., 1978). These assumptions are well-documented in previous studies, and due to the importance of early experiences and parent-child relationship, the attachment quality in adulthood is often discussed within the context of early experiences with parents (Bakermans-Kranenburg \& van IJzendoorn, 2016). As previously indicated, besides relationships with romantic partners, friendships can also be influenced by the relationship with parents. According to Fraley and Roisman (2015), the development of close friendships is one of the pathways through which early attachment affects functioning in romantic relationships as well. Previous studies revealed small to moderate associations between early attachment and close friendships (Schneider et al., 2001), and also indicated that the quality of attachment to parents predicted friendship quality (Rubin et al., 2004).

Both mothers and fathers create a context for the development of an internal working model relevant to attachment behavior and quality. However, previous studies also revealed some differences regarding parental gender, 
implying that parental practices should be assessed separately. One of the most mentioned difference is that a relationship with a mother is often described as closer but at the same time as more conflicting than a relationship with a father (Sharf \& Mayseless, 2008). McKinney and Renk (2008) obtained that late adolescents generally perceived their mothers more often as authoritative and fathers as authoritarian. On a sample of university undergraduates, Trinke and Bartholomew (1997) reported that mothers are perceived as a secure base more often than fathers, and in a study conducted by Doyle et al. (2009), adolescents displayed more secure attachment with mothers than with fathers. In a study conducted by Shek and Dou (2020), adolescents attributed the higher level of parental control to mothers but also reported a better relationship with mothers. These differences are displayed in parental self-ratings as well. Gugliandolo et al. (2019) obtained that mothers rated themselves higher on supportiveness and warmth, but psychological control and physical coercion as well. Literature generally suggests that mothers express more supportiveness and warmth, but at the same time, they are also more prone to parental control. Concerning parental control, it should be noticed that this construct, depending on its measures, can refer to various strategies to regulate a child's behavior, including those related to harsh discipline and psychological control or intrusiveness that contribute to a child's emotional and socially dysfunctional behavior (León-del-Barco et al., 2019; Soenens \& Vankiste, 2010), and further reflect on peer-relationships. Regarding gender differences in parental practices, it is justified to assume that the effects of specific parental behavior on attachment can be different depending on the parent's gender. Besides, La Guardia et al. (2000) report that the attachment to fathers displays more variability than attachment to mothers. The literature also indicates that adults with different types of attachment can have different memories of their parents' behavior (and childhood in general). Main et al. (1985) obtained that adults with secure attachment had positive memories of their parents, while insecurely attached individuals described their parents as cold or rejecting, or their memories included mixed emotions regarding their parents' supportiveness. Similarly, Mikulincer and Shaver (2016) point out that insecurely attached individuals perceive that they have less available and less satisfying support, and, in some cases, their dissatisfaction with received support arises from the perception that it exceeds their actual needs. Literature also supports the presumption that adults with secure attachment in close relationships (with friends or romantic partners) are more likely to perceive interaction with others more positively and have a more positive perception of their parents (Jones et al., 2015).

\subsection{Present Study}

This study aimed to examine whether there is a simultaneous effect of personality traits and perceived parental behavior on the dimensions of attachment to close friends among young women. In line with the literature, the assumption is that extraversion and agreeableness will be negative predictors of both attachment anxiety and attachment avoidance, while neuroticism will be the strongest positive predictor of attachment anxiety. Since attachment avoidance and neuroticism presumably represent different affect regulation systems, the association between neuroticism and attachment avoidance is not expected. The association of openness and attachment dimensions is also not expected, and due to previous ambiguous results regarding the association of conscientiousness with attachment dimensions, a specific hypothesis is not defined in this case.

Concerning the effects of parental behavior, the assumption is that parental support will be a negative predictor of attachment anxiety and avoidance. Although previous studies reported somewhat ambiguous findings regarding the role of parental control in adult attachment, the assumption is that restrictive control will positively predict both attachment dimensions.

Finally, the assumption is that the effects of personality will be stronger than the effects of perceived parental behavior. However, it is also expected that the combination of these predictors significantly adds to the prediction of both attachment dimensions, especially concerning the mother's parental behavior.

\section{Methodology}

\subsection{Participants and Procedure}

Participants were 287 female students from the University of Zagreb (Croatia), and the average age of participants was $M=21.64$ ( $S D=1.842$; age range: $19-35)$. Participation in the study was anonymous and voluntary, and upon obtaining consent, participants filled out the questionnaire during one of the regular classes.

\subsection{Instruments}

For the purposes of this study Big Five Inventory (BFI, John et al., 2008), consisting of 44 items, was used to assess five personality traits - extraversion, agreeableness, conscientiousness, neuroticism, and openness to experience. Participants rated themselves in terms of agreement with each item on a scale from 1 (strongly disagree) to 5 (strongly agree). The total score on each subscale is calculated as an average score of associated items. Previous 
validations of this instrument for the countries of Eastern Europe demonstrated clear replicability of the proposed factor structure (Schmitt et al., 2007). Subscales for each trait demonstrated good Cronbach's alpha coefficients $(\alpha)$ ranging from 0.75 through 0.87 .

Further, participants evaluated parental behavior of their parents via Parental Behavior Questionnaire URP-29 (Brković et al., 2012); a 29-item instrument validated in Croatian cultural context and measuring three global dimensions of parental behavior - parental support (including warmth, encouraging child's autonomy, inductive reasoning and knowledge about child's activities and whereabouts), restrictive control (referring to punishment and intrusiveness), and permissiveness. For the purposes of this study, two dimensions were examined: parental support (16 items) and restrictive control (10 items). Participants estimated the extent to which each item refers to the behavior of their mothers and fathers (separately) on a scale from 1 (not at all like her/him) to 4 (completely like her/him). The total score on each dimension is calculated as an average of associated items, and Cronbach's alpha coefficients ranged from 0.81 to 0.93 .

Attachment to close friends was assessed by the Experiences in Close Relationship Scale (Kamenov \& Jelić, 2003). This instrument is a shortened and validated version of Brennan's Experiences in Close Relationships Inventory (Brennan et al., 1998), consisting of 18 items and measuring anxiety (9 items) and avoidance (9 items) as attachment dimensions in close relationships. The scale has three different versions (for assessment of romantic relationships, friendships, and family relationships), and in this study version for assessing friendship was used. Participants rated the extent to which each statement refers to a relationship with their best friend on a scale from 1 (strongly disagree) to 7 (strongly agree). The total score on each dimension is calculated as a sum of item-ratings. Cronbach's alpha coefficient was 0.83 for attachment anxiety and 0.81 for attachment avoidance, respectively.

\section{Results}

Previous to analyses, descriptive statistics for each variable are presented in Table 1.

Table 1. Means, standard deviations, and reliabilities for attachment dimensions, personality traits, and perceived parental behavior

\begin{tabular}{llllll}
\hline & $M$ & $S D$ & $\min$ & $\max$ & $\alpha$ \\
\hline Attachment dimensions & & & & & \\
$\quad$ Attachment anxiety & 22.68 & 8.891 & 9 & 52 & 0.83 \\
$\quad$ Attachment avoidance & 17.61 & 7.523 & 9 & 46 & 0.81 \\
Personality traits & & & & & \\
$\quad$ Extraversion & 3.56 & 0.668 & 1.88 & 5.00 & 0.81 \\
Agreeableness & 3.85 & 0.555 & 2.56 & 4.89 & 0.75 \\
Conscientiousness & 3.51 & 0.714 & 1.44 & 5.00 & 0.87 \\
Openness & 3.60 & 0.665 & 2.00 & 5.00 & 0.86 \\
$\quad$ Neuroticism & 2.60 & 0.673 & 1.00 & 4.38 & 0.81 \\
Parental behavior & & & & & \\
$\quad$ Mothers' parental supportiveness & 3.36 & 0.505 & 1.56 & 4.00 & 0.90 \\
Mothers' restrictive control & 2.09 & 0.578 & 1.00 & 3.90 & 0.81 \\
Fathers' parental supportiveness & 2.88 & 0.676 & 1.00 & 4.00 & 0.93 \\
Fathers' restrictive control & 1.84 & 0.588 & 1.00 & 3.70 & 0.83 \\
\hline
\end{tabular}

Results presented in Table 1 indicate that the average results of attachment anxiety, attachment avoidance, and neuroticism are shifted towards lower scale values, while the average results on extraversion, agreeableness, conscientiousness, and openness are shifted towards higher values. Having in mind that participants in this study are students who track a career in the educational sector, these values regarding personality traits are not surprising. Namely, personality is also related to professional interests. Hence, those who chose professions that include work with others and are more likely to be higher on extraversion, agreeableness, and openness to experience (Berings et al., 2004). Additionally, recent studies imply that the student population, compared to others, could be generally higher on extraversion and agreeableness due to the effect of higher education context (Kassenboehmer et al., 2018). Results displayed in Table 1 also reveal that the supportiveness of both mothers and fathers is, on average, rated relatively high. Mothers are rated higher than fathers on both dimensions of parental behavior, which is in 
line with some previous findings (Olivari et al., 2015) and could imply that participants interact with their mothers more often (Ducharme et al., 2002). This explanation seems especially plausible, having in mind that participants in this study were young women, and the literature emphasizes the closeness of the mother-daughter relationship (Van Lissa et al., 2018).

The effects of personality traits and mothers' and fathers' parental behavior on each dimension of attachment to close friends were tested by multiple regression analyses. The results of the analyses are displayed in Table 2 .

Table 2. Results of multiple regression analyses with personality traits and dimensions of perceived parental behavior as predictors and dimensions of attachment to close friends as criterion variables

\begin{tabular}{lcccc}
\hline & \multicolumn{2}{c}{ Anxiety } & \multicolumn{2}{c}{ Avoidance } \\
\cline { 2 - 5 } & $\beta$ & $t$ & -.14 & $-2.15^{*}$ \\
\hline Extraversion & -.10 & -1.59 & -.19 & $-2.63^{* *}$ \\
Agreeableness & -.18 & $-2.56^{* *}$ & -.10 & 1.59 \\
Conscientiousness & .13 & $2.10^{*}$ & .12 & 1.89 \\
Openness & .04 & 0.67 & .05 & 0.64 \\
Neuroticism & .37 & $5.32^{* *}$ & -.25 & $-3.42^{* *}$ \\
Mother's parental supportiveness & -.01 & -0.13 & -.15 & $-2.12^{*}$ \\
Mother's restrictive control & .03 & 0.40 & .16 & $2.28^{*}$ \\
Father's parental supportiveness & .06 & 0.88 & .05 & 0.66 \\
Father's restrictive control & .09 & 1.47 & $R^{2}=0.17 ; F=4.90^{* *}$ \\
\hline
\end{tabular}

Note. $*=p<.05 ; * *=p<.01$.

According to results displayed in Table 2, agreeableness was, as hypothesized, a negative predictor of both anxiety and avoidance. Anxiety was also positively predicted by neuroticism, but by conscientiousness as well. Finally, extraversion was a negative predictor of avoidance, and openness was not a significant predictor of attachment dimensions. As far as the personality traits are concerned, it seems that participants with higher scores on extraversion and agreeableness are less avoidant in close friendship. On the other side, the participants who are more likely to be anxious in close friendship are not only those with higher scores on neuroticism (as expected) but those with higher scores on conscientiousness as well. Due to the direction of this latter association, zero-order correlations were additionally examined. Since the zero-order correlation between conscientiousness and attachment anxiety was not significant $(r=.08 ; p>.05)$, and conscientiousness significantly correlated with neuroticism $(r=-.31 ; p<.01)$, the effect of conscientiousness in regression analysis called upon additional clarification. Therefore, this effect is further explored according to some previous findings that imply a more complex association of neuroticism and conscientiousness in predicting attachment anxiety. Crawford et al. (2007) point out the potential moderating role of conscientiousness; however, results obtained in this study indicated a potentially stronger effect of neuroticism on attachment anxiety than the direct effect of conscientiousness itself. Hence, the presumed mediation role of neuroticism is further examined by the PROCESS macro (Hayes, 2018), and the results (Figure 1) indicate that there is no direct effect of conscientiousness on attachment anxiety and that this relationship is mediated by neuroticism through its negative correlation with conscientiousness and positive correlation with attachment anxiety. More specifically, a lower level of conscientiousness leads to a higher level of neuroticism, and the higher the neuroticism, the higher is the level of attachment anxiety.

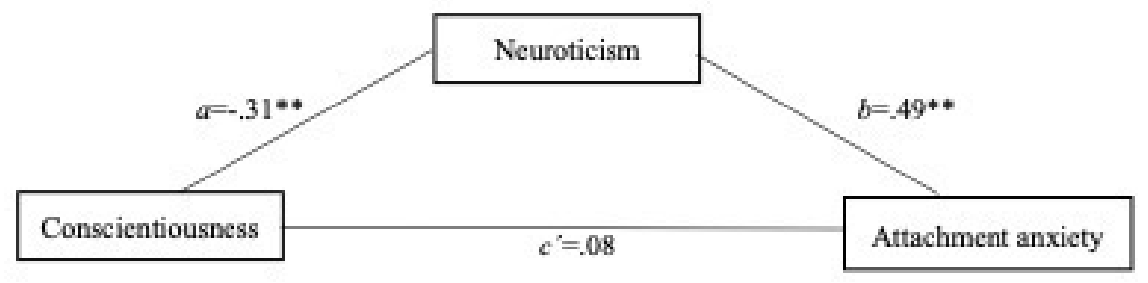

Figure 1. Mediating effect of neuroticism on the association between conscientiousness and anxiety 
Concerning the effects of parental behavior, these effects were not significant in the case of attachment anxiety, i.e., only personality traits significantly contributed to the prediction of this attachment dimension. However, parental behavior predicted attachment avoidance. More specifically, mother's supportiveness and restrictive control were negative predictors of attachment avoidance, while father's parental support was a positive predictor of this dimension. These results imply that participants whose mothers are at the same time both less supportive and less controlling and whose fathers are more supportive express a higher level of attachment avoidance in close friendships.

\section{Discussion}

In line with the aim of this study, the simultaneous effects of personality traits and perceived parental behavior in predicting attachment anxiety and avoidance in close friendship were examined. The results confirmed some of the starting points, and the hypotheses related to this research question are partially confirmed. Generally, it can be concluded that a combination of personality traits and perceived parental behavior significantly contributes to the prediction of the attachment avoidance dimension, whereas the attachment anxiety dimension is predicted by personality traits only.

As hypothesized, neuroticism was a positive predictor of attachment anxiety, which is a finding consistent with previous studies. Crawford et al. (2007) noted that simple bivariate correlations between these two constructs are usually between .40 and .50 (value of $r=.45$ obtained in this study is also within that range). Hence, it was reasonable to assume that neuroticism, compared to other personality traits, would have the highest loading in predicting attachment anxiety. This association appears to be pertinent in close friendships as well, confirming the assumption that it is stable across different types of close relationships, samples, and cultures (Marušić et al., 2011). Since individuals with higher scores on neuroticism are generally more prone to negative affect, i.e., worrying about rejection and availability of close person's support, this trait was meaningfully associated with anxious attachment, implying that both neuroticism and attachment anxiety could be manifestations of insecurity. Openness did not predict attachment dimensions, and this finding is in line with some previous studies (Noftle \& Shaver, 2006). This study also supported the assumption on the complexity of the relationship between conscientiousness and neuroticism in predicting attachment anxiety, as suggested by the literature (Crawford et al., 2007). The results indicated that conscientiousness had no direct effect on attachment anxiety; however, neuroticism appears to mediate this relationship through its negative correlation with conscientiousness and positive correlation with attachment anxiety. Presumably, the lack of self-control, reliability, and order (components of conscientiousness) can result in poor affect regulation, and a higher level of distress and negative affect (components of neuroticism) can further result in higher attachment anxiety in close friendship.

In the case of attachment avoidance, results indicated that two personality traits were significant predictors of this dimension - extraversion and agreeableness. This finding supports the assumption on the relevance of these traits in interpersonal relationships and confirms the consistency of these associations (Mikulincer \& Shaver, 2016). Avoidant individuals are generally prone to actively avoid intimacy and to be self-sufficient. Accordingly, obtained associations are meaningful since individuals who have lower scores on extraversion and agreeableness are more likely to engage in various avoidant strategies. Namely, a lower level of gregariousness, sociability, and warmth (i.e., lower extraversion) induces behaviors aimed at avoiding closeness with others. Similarly, a decreased level of trust, empathy, altruism, and modesty (i.e., lower agreeableness) also contributes to the avoidance of intimacy. The importance of agreeableness for both attachment dimensions is also supported by the literature on romantic relationships and can extend to close friendships. Mikulincer and Shaver (2016) point out that anxious individuals are preoccupied with doubts about another person's availability, and these doubts contrast with agreeableness, while avoidant individuals have negative internal working models of others that contrast with trust (as a characteristic of agreeableness). Unlike in the case of attachment avoidance, extraversion was not a significant predictor of attachment anxiety, which is in line with some other studies (e.g., Hanak \& Dimitrijevic, 2013; Hart et al.; Noftle \& Shaver, 2006), confirming that the association between extraversion and attachment anxiety appears to be less consistent. Based on previous studies, it seems that the association between extraversion and attachment anxiety can be expected on the level of zero-order correlations and regarding one or two specific facets of extraversion. On the other hand, more facets of extraversion display consistent association with attachment avoidance.

Concerning parental behavior, the results of this study generally demonstrated that parental behavior was one of the factors predictive for attachment avoidance. However, parental behavior did not predict attachment anxiety. The absence of parental behavior effects in predicting attachment anxiety and their presence in predicting attachment avoidance could relate to possible genetic influences. According to Crawford, Livesley, et al. (2007), it 
is plausible that genetic influences significantly account for explaining anxiety, but not avoidance. That could further imply that environmental factors, including parental behavior, have more effects on attachment avoidance.

The results indicated that lower levels of mother's parental supportiveness and restrictive control predicted increased attachment avoidance. These results imply that young women who perceive that their mothers were generally more involved in various parental behaviors are less prone to avoid intimacy with close friends, regardless of whether this involvement refers to parental supportiveness or restrictive control. The association between mother's parental supportiveness and attachment avoidance is in line with the literature. Attachment avoidance is an indicator of insecure attachment, and according to Mikulincer and Shaver (2016), individuals who are insecurely attached are more likely to be less satisfied with the support received from significant others and perceive them as less supportive. Within the context of this study, this can apply to the perception of the mother's parental support. As previously mentioned, the same direction of association was obtained for the mother's restrictive control. Literature suggests that mothers are perceived at the same time as more supportive and controlling (Olivari et al., 2015), and the association of generally higher ratings on both dimensions could reflect overall more frequent interaction with mothers (Ducharme et al., 2002).

Moreover, the father's support appeared to be a positive predictor of attachment avoidance. Although this association was unexpected, there are some indications (drawn from the studies on romantic relationships) that could extend to close friendships and offer plausible explanations. Namely, Brock and Lawrence (2014) reported that avoidant individuals perceive that their spouses give them more support than needed, which is in line with the tendency of avoidant people to be distant and self-sufficient. Some other studies also point out the difference between dominantly anxious and dominantly avoidant individuals. A study conducted by Zhang and Hazan (2002) demonstrated that avoidant individuals have a more stable negative perception of others, compared to anxiously attached individuals. Applied in the context of this study, and having in mind some differences in perception of parental behavior concerning parental gender aforesaid in this paper, the perception of more support than needed could be more likely to occur in the case of fathers. Namely, mothers are expected to express more emotions in everyday interaction with children, including emotions related to support. Further, in adolescence, the inclination to share feelings with mothers increases, and closeness with fathers diminishes, especially in the father-daughter relationship (Laursen \& Collins, 2004). Van Lissa et al. (2018) also emphasize the closeness of the mother-daughter relationship and imply a more salient role of supportiveness in this relationship. Accordingly, if the interaction with fathers (including supportive interaction) is more intense than expected, it could be perceived as excessive or invasive by daughters who are prone to avoidance.

Conclusively, the main findings of this study are in line with previous research and add to the current base of knowledge by providing evidence for the simultaneous effect of personality and parental behavior in explaining attachment to close friends. This study also indicated the need for further research of complex interaction of specific personality traits in predicting attachment quality, as well as the differential roles of mother's and father's parental behavior as environmental factors contributing to the adult attachment.

\subsection{Limitations of the Study and Recommendations}

Some limitations of this study should also be addressed. First, since only young women participated in this study, these results cannot be generalized either to close male friendships or to other stages of adulthood. Besides, the sample is relatively homogenous concerning all measured variables. The correlational nature of this study also represents a difficulty in generalizing results, as well as the question of self-reported measures' accuracy.

Further studies in this field of interest could address these limitations. Accordingly, it would be worthwhile to explore are the patterns of these predictors the same in the case of young men's attachment to close friends. Moreover, future studies could also assess obtained prediction patterns on generally more heterogenous samples (especially concerning personality traits), with a particular focus on attaining more detailed insight into complex interaction of neuroticism, conscientiousness, and attachment anxiety. Besides, it would also be useful to have close friends' ratings as an additional indicator of participants' attachment in close friendship. Finally, collecting data from parents as a supplementary source of information on parental behavior should also be included.

\section{References}

Ainsworth, M. D. S., Blehar, M. C., \& Wall, S. (1978). Patterns of attachment: A psychological study of the Strange Situation. Hillsdale, NJ: Lawrence Erlbaum.

Allen, J. P., \& Tan, J. S. (2016). The multiple facets of attachment in adolescence. In J. Cassidy \& P. R. Shaver (Eds.), Handbook of Attachment: Theory, research, and clinical applications (pp. 399-415). New York, NY: Guilford Press. 
Amati, V., Meggiolaro, S., Rivellini, G., \& Zaccarin, S. (2018). Social relations and life satisfaction: The role of friends. Genos, 74(1), Article 71. https://doi.org/10.1186/s41118-018-0032-z

Arnett, J. J. (2000). Emerging adulthood: a theory of development from the late teens through the twenties. American Psychologist, 55(5), 469-480. https://doi.org/10.1037/0003-066X.55.5.469

Bakermans-Kranenburg, M. J., \& van IJzendoorn, M. H. (2016). Attachment, parenting, and genetics. In J. Cassidy \& P. R. Shaver (Eds.), Handbook of Attachment: Theory, research, and clinical applications (pp. 155-179). New York, NY: Guilford Press.

Bartholomew, K. (1990). Avoidance of intimacy: An attachment perspective. Journal of Social and Personality Relationships, 7, 147-178. https://doi.org/10.1177/0265407590072001

Bartholomew, K., \& Horowitz, L. M. (1991). Attachment styles among young adults: A test of a four-category model. Journal of Personality and Social Psychology, 61(2), 226-244. https://doi.org/10.1037/0022-3514.61.2.226

Berings, D., De Fruyt, F., \& Bouwen, R. (2004). Work values and personality traits as predictors of enterprising and social vocational interests. Personality and Individual Differences, 36(2), 349-364. https://doi.org/10.1037/t12411-000

Bowlby, J. (1989). The making and breaking of affectional bonds. London: Routledge.

Brennan, K. A., Clark, C. L., \& Shaver, P. R. (1998). Self-report measures of adult romantic attachment. An integrative overview. In J. A. Simpson \& W. S. Rholes (Eds.), Attachment theory and close relationships (pp. 46-76). New York, NY: Guilford.

Brock, R. L., \& Lawrence, E. (2014). Intrapersonal, interpersonal, and contextual risk factors for overprovision of partner support in marriage. Journal of Family Psychology, 28(1), 54-64. https://doi.org/10.1037/a0035280

Buist, K. L., Reitz, E., \& Deković, M. (2008). Attachment stability and change during adolescence: A longitudinal application of the Social Relations Model. Journal of Social and Personal Relationships, 25(3), 429-444. https://doi.org/10.1177/0265407508090867

Chopik, W. J., Edelstein, R. S., \& Grimm, K. J. (2019). Longitudinal changes in attachment orientation over a 59-year period. Journal of Personality and Social Psychology, 116(4), 598-611. https://doi.org/10.1037/pspp0000167

Chung, S. (2018). Attachment orientations and relationship maintenance in college friendships (Publication No. 1280) [Doctoral dissertation, Washington University in St. Louis]. Arts and Sciences Electronic Thesis and Dissertations. Retrieved from https://openscholarship.wustl.edu/art_sci_etds/1280

Crawford, T. N., Shaver, P. R., \& Goldsmith, H. H. (2007). How affect regulation moderates the association between anxious attachment and neuroticism. Attachment \& Human Development, 9(2), 95-109. https://doi.org/10.1080/14616730701349747

Crawford, T. N., Livesley, W. J., Jang, K. L., Shaver, P. R., Cohen, P., \& Ganiban, J. (2007). Insecure attachment and personality disorder: A twin study of adults. European Journal of Personality, 21, 191-208. https://doi.org/10.1002/per.602

Donnellan, M. B., Burt, S. A., Levendosky, A. A., \& Klump, K. L. (2008). Genes, personality, and attachment in adults: A multivariate behavioral genetic analysis. Personality and Social Psychology Bulletin, 34(1), 3-16. https://doi.org/10.1177/0146167207309199

Doyle, A. B., Lawford, H., \& Markiewicz, D. (2009). Attachment style with mother, father, best friend, and romantic partner during adolescence. Journal of Research on Adolescence, 19(4), 690-714. https://doi.org/10.1111/j.1532-7795.2009.00617.x

Ducharme, J., Doyle, A. B., \& Markiewiz, D. (2002). Attachment security with mother and father: Associations with adolescents' reports of interpersonal behavior with parents and peers. Journal of Social and Personal Relationships, 19(2), 203-231. https://doi.org/10.1177/0265407502192003

Fraley, R. C., \& Roisman, G. I. (2015). Early attachment experiences and romantic functioning: Developmental pathways, emerging issues, and future directions. In J. A. Simpson \& W. S. Rholes (Eds.), Attachment theory and research: New directions and emerging themes (pp. 9-38). New York, NY: The Guilford Press. 
Fransson, M., Granqvist, P., Bohlin, G., \& Hagekull, B. (2013). Interlinkages between attachment and the Five-Factor Model of personality in middle childhood and young adulthood: a longitudinal approach. Attachment and Human Development, 15(2), 219-239. https://doi.org/10.1080/14616734.2013.754985

Gilespie, B. J., Lever, J., Frederick, D., \& Royce, T. (2015). Close adult friendships, gender, and the life cycle. Journal of Social and Personal Relationships, 32(6), 709-736. https://doi.org/10.1177/0265407514546977

Gillath, O., Karantzas, G. C., \& Selcuk, E. (2017). A net of friends: Investigating friendship by integrating attachment theory and social network analysis. Personality and Social Psychology Bulletin, 43(11), 1546-1565. https://doi.org/10.1177/0146167217719731

Gugliandolo, M. C., Costa, S., Cuzzocrea, F., \& Larcan, R. (2019). Parenting styles and psychological control: Similarities and differences between mothers and fathers of school-age children. Journal of Clinical and Developmental Psychology, 1(3), 22-29. https://doi.org/10.6092/2612-4033/0110-2159

Hall, J. A. (2011). Sex differences in friendship expectations: A meta-analysis. Journal of Social and Personal Relationships, 28(6), 723-747. https://doi.org/10.1177/0265407510386192

Hanak, N., \& Dimitrijevic, A. (2013). A Serbian version of Modified and revised Experiences in Close Relationship Scale (SM-ECR-R). Journal of Personality Assessment, 95(5), 530-538. https://doi.org/10.1080/00223891.2013.778271

Harris, K., \& Vazire, S. (2016). On friendship development and the Big Five personality traits. Social and Personality Psychology Compass, 10, 647-667. https://doi.org/10.1111/spc3.12287

Hart, J. J., Nailling, E., Bizer, G. Y., \& Collins, C. K. (2015). Attachment theory as a framework for explaining engagement with Facebook. Personality and Individual Differences, 77, 33-40. https://doi.org/10.1016/j.paid.2014.12.016

Hartup, W. W., \& Stevens, N. (1997). Friendships and adaptation in the life course. Psychological Bulletin, 121, 355-370. https://doi.org/10.1037/0033-2909.121.3.355

Hayes, A. F. (2018). Introduction to mediation, moderation, and conditional process analysis: a regression-based approach. New York, NY: Guilford Press.

Hershenberg, R., Davila, J., Yoneda, A., Starr, L. R., Ramsay Miller, M., Stroud, C. B., \& Feinstein, B. A. (2011). What I like about you: The association between adolescent attachment security and emotional behavior in a relationship promoting context. Journal of Adolescence, 34, 1017-1024. https://doi.org/10.1016/j.adolescence.2010.11.006

John, O. P., Naumann, L. P., \& Soto, C. J. (2008). Paradigm shift to the integrative Big-Five trait taxonomy: History, measurement, and conceptual issues. In O. P. John, R. W. Robins, \& L. A. Pervin (Eds.), Handbook of personality: Theory and research (pp. 114-158). New York, NY: Guilford Press.

Jones, J. D., Cassidy, J., \& Shaver, P. R. (2015). Adult attachment style and parenting. In J. A. Simpson \& W. S. Rholes (Eds.), Attachment theory and research: New directions and emerging themes (pp. 234-260). New York, NY: The Guilford Press.

Kamenov, Ž., \& Jelić, M. (2003). Validation of adult attachment measure in various types of close relationships: Modification of Brennan's Experiences in Close Relationship Inventory. Suvremena psihologija, 6(1), 73-91.

Kassenboehmer, S., Leung, F., \& Schurer, S. (2018). University education and non-cognitive skills development. Oxford Economic Papers, Oxford University Press, 70(2), 538-562. https://doi.org/10.1093/oep/gpy002

Keizer, R., Helmerhorst, K. O. W., \& van Rijn-van Gelderen, L. (2019). Perceived Quality of the mother-adolescent and father-adolescent attachment relationship and adolescents' self-esteem. Journal of Youth and Adolescence, 48, 1203-1217. https://doi.org/10.1007/s10964-019-01007-0

Keresteš, G., Brković, I., Kuterovac Jagodić, G., \& Greblo, Z. (2012). Development and validation of Parental Behavior Questionnaire. Suvremena psihologija, 15(1), 23-42. https://doi.org/10.1037/t69232-000

La Guardia, J. G., Ryan, R. M., Couchman, C. E., \& Deci, E. L. (2000). Within-person variation in security of attachment: A self-determination theory perspective on attachment, need fulfillment, and well-being. Journal of Personality and Social Psychology, 79(3), 367-384. https://doi.org/10.1037/0022-3514.79.3.367

Lai, Y.-H., \& Carr, S. (2018). A critical exploration of child-parent attachment as a contextual construct. Behavioral Sciences, 8, Article 112. https://doi.org/10.20944/preprints201811.0228.v1 
Laursen, B., \& Collins, W. A. (2004). Parent-child communication during adolescence. In A. L. Vangelisti (Eds.), Handbook of Family Communication (pp. 333-348). Mahwah, NJ: Lawrence Erlbaum.

León-del-Barco, B., Mendo-Lázaro, S., Polo-del-Rio, M. I., \& López-Ramos, V. M. (2019). Parental psychological control and emotional and behavioral disorders among Spanish adolescents. International Journal of Environmental Research and Public Health, 16(3), Article 507. https://doi.org/10.33907ijerph16030507

Main, M., Kaplan, N., \& Cassidy, J. (1985). Security in infancy, childhood, and adulthood: A move to the level of representation. Monographs of the Society for Research in Child Development, 50(1/2), 66-104. https://doi.org/10.2307/3333827

Marušić, I., Kamenov, Ž., \& Jelić, M. (2011). Personality and attachment to friends. Društvena istraživanja, 114(4), 1119-1137. https://doi.org/10.5559/di.20.4.10

McCrae, R. R., \& Costa, P. T. (1997). Personality trait structure as a human universal. American Psychologist, 52(5), 509-516. https://doi.org/10.1037/0003-066X.52.5.509

McKinney, C., \& Renk, K. (2008). Differential parenting between mothers and fathers: Implications for late adolescents. Journal of Family Issues, 29, 806-827. https://doi.org/10.1177/0192513X07311222

Miething, A., Almquist, Y. B., Östberg, V., Rostila, M., Edling, C., \& Rydgren, J. (2016). Friendship networks and psychological well-being from late adolescence to young adulthood: A gender-specific structural equation modeling approach. BMC Psychology, 4, Article 34. https://doi.org/10.1186/s40359-016-0143-2

Mikulincer, M., \& Shaver, P. R. (2016). Boosting attachment security in adulthood: The "broaden-and-build" effects of security enhancing mental representations and interpersonal contexts. In J. A. Simpson \& W. S. Rholes (Eds.), Attachment theory and research: New directions and emerging themes (pp. 124-144). New York, NY: The Guilford Press.

Murakami, T. (2014). Relation between attachment styles and friendship motivation in university students. The Japanese Journal of Personality, 22(3), 289-292. https://doi.org/10.2132/personality.22.289

Noftle, E. E., \& Shaver, P. R. (2006). Attachment dimensions and the Big Five personality traits: Associations and comparative ability to predict relationship quality. Journal of Research in Personality, 40, 179-208. https://doi.org/10.1016/j.jrp.2004.11.003

Olivari, M. G., Hertfelt Wahn, E., Maridaki-Kassotaki, K., Antonopoulou, K., \& Confalonieri, E. (2015). Adolescent perceptions of parenting styles in Sweden, Italy and Greece: An exploratory study. Europe's Journal of Psychology, 11(2), 244-258. https://doi.org/10.5964/ejop.v11i2.887

Rholes, W. S., \& Simpson, J. A. (2015). New directions and emerging themes in attachment theory and research. In J. A. Simpson \& W. S. Rholes (Eds.), Attachment theory and research: New directions and emerging themes (pp. 1-7). New York, NY: The Guilford Press.

Rubin, K. H., Dwyer, K. M., Booth-LaForce, C., Kim, A. H., Burgess, K. B., \& Rose-Krasnor, L. (2004). Attachment, friendship, and psychosocial functioning in early adolescence. Journal of Early adolescence, 24(4), 326-256. https://doi.org/10.1177/0272431604268530

Scharf, M., \& Mayeseless, O. (2008). Late adolescent girls' relationship with parents and romantic partner: The distinct role of mothers and fathers. Journal of Adolescence, 31, 837-855. https://doi.org/10.1016/j.adolescence.2008.06.012

Scharfe, E., Pitman, R., \& Cole, V. (2017). Function of attachment hierarchies in young adults experiencing the transition from university. Interpersona - An International Journal on Personal Relationships, 11(1), 40-54. https://doi.org/10.5964/ijpr.v11i1.223

Schmitt, D. P., Allik, J., McCrae, R. R., \& Benet-Martinez, V. (2007). The geographic distribution of Big Five personality traits. Journal of Cross-Cultural Psychology, 38(2), 173-212. https://doi.org/10.1177/0022022106297299

Schneider, B. H., Atkinson, L., \& Tardiff, C. (2001). Child-parent attachment and children's peer relations. Developmental Psychology, 37, 86-100. https://doi.org/10.1037/0012-1649.37.1.86

Shaver, P. R., \& Brennan, K. A. (1992). Attachment styles and the "Big Five" personality traits: Their connections with each other and with romantic relationship outcomes. Personality and Social Psychology Bulletin, 18(5), 536-545. https://doi.org/10.1177/0146167292185003 
Shek, D. T. L., \& Dou, D. (2020). Perceived parenting and parent-child relational qualities in fathers and mothers: Longitudinal findings based on Hong Kong adolescents. International Journal of Environmental Research and Public Health, 17(11), Article 4083. https://doi.org/10.3390/ijerph17114083

Soenens, B., \& Vankiste, M. (2010). A theoretical upgrade of the concept of parental psychological control: Proposing new insights on the basis of self-determination theory. Developmental Review, 30(1), 74-99. https://doi.org/10.1016/j.dr.2009.11.001

Thompson, R. A. (2016). Early attachment and later development: Reframing the questions. In J. Cassidy \& P. R. Shaver (Eds.), Handbook of Attachment: Theory, research and clinical applications (pp. 330-348). New York, NY: Guilford Press.

Trinke, S. J., \& Bartholomew, K. (1997). Hierarchies of attachment relationships in young adulthood. Journal of Social and Personal Relationships, 14(5), 603-625. https://doi.org/10.1177/0265407597145002

Van Lissa, C. J., Keizer, R., Van Lier, P. A. C., Meeus, W. H. J., \& Branje, S. (2018). The role of fathers' versus mothers' parenting in emotion regulation development from mid-late adolescence: Disentangling between-family differences from within-family effects. Developmental Psychology, 55(2), 377-389. https://doi.org/10.31234/osf.io/fkh5q

Young, E. S., Simpson, J. A., Griskevicius, V., Huelsnitz, C. O., \& Fleck, C. (2017). Childhood attachment and adult personality: A life history perspective. Self and Identity, 18(1), 1-17. https://doi.org/10.1080/15298868.2017.1353540

Zeifman, D. M., \& Hazan, C. (2016). Pair bonds as attachment: Mounting evidence in support of Bowlby's hypothesis. In J. Cassidy \& P. R. Shaver (Eds.), Handbook of Attachment: Theory, research, and clinical applications (pp. 416-434). New York, NY: Guilford Press.

Zhang, F., \& Hazan, C. (2002). Working models of attachment and person perception processes. Personal Relationships, 9, 225-235. https://doi.org/10.1111/1475-6811.00015

\section{Copyrights}

Copyright for this article is retained by the author(s), with first publication rights granted to the journal.

This is an open-access article distributed under the terms and conditions of the Creative Commons Attribution license (http://creativecommons.org/licenses/by/4.0/). 